\title{
On crushing characteristics of hybrid sandwich aluminum-cardboard panels reinforced with glass fiber composite rods
}

https://doi.org/10.1515/secm-2019-0006

Received June 13, 2018; accepted November 16, 2018

\begin{abstract}
This paper explores crashworthiness properties of different configurations of stacked aluminumcardboard panels reinforced with braided glass fiberepoxy rods manufactured using a tubular braiding machine through quasi-static compression tests. Compression tests are performed on five different hybrid structures involving two layers of cardboard with varying number and stacking configuration of aluminum supports compared with two-layer cardboard panels maintaining five rods in each layer for all cases. The results show that two-layer cardboard panels reinforced with rods have poor crushing performance due to instability of the rods in the adjacent cardboard layers. Moreover, considering crushing performance and weight, panels with one aluminum support in between cardboard layers perform the best, because the load exerted on each rod is transferred to the aluminum support, and then transferred uniformly to the adjacent rods ensuring stability and progressive crushing behavior. When this stacking sequence is repeated in panels of increased thickness with three and four layers of cardboard and two and three layers of aluminum, respectively, crushing stability is reduced due to the relatively small surface area of the panels. In addition, increasing the panel area for a given number of layers and rods does not negatively affect the crushing stability of the panels.
\end{abstract}

Keywords: aluminum, GFRP, braided rods, hybrid sandwich panels, crashworthiness, progressive crushing

\footnotetext{
*Corresponding Author: Gabriel Y. Fortin: Department of Advanced Fibro-Science, Kyoto Institute of Technology, Matsugasaki, Sakyo-ku, Kyoto, 606-8585, Japan, E-mail: gabriel.fortin5@gmail.com

Elsayed A. Elbadry: Department of Advanced Fibro-Science, Kyoto Institute of Technology, Matsugasaki, Sakyo-ku, Kyoto, 606-8585, Japan

Mining and Metallurgical Engineering Department, Faculty of Engineering, Assiut University, Assiut 71515, Egypt

Hiroyuki Hamada: Department of Advanced Fibro-Science, Kyoto Institute of Technology, Matsugasaki, Sakyo-ku, Kyoto, 606-8585, Japan
}

\section{Introduction}

Ensuring that the automobiles of the future are safer in terms of crashworthiness with minimal carbon footprint are ongoing challenges that we face. According to the latest report from the International Organization of Motor Vehicle Manufacturers (OICA), approximately 70 million passenger cars were produced in 2017 [1]. Clearly, automotive structures must make greater use of materials that are both light and strong in order to minimize environmental impacts and to ensure structural integrity during a crash event. Composite materials, particularly fiber-reinforced plastics, are an excellent candidate for meeting these requirements. They are lightweight, stiff, and strong materials that provide weight savings and improved fuel efficiency in service. In addition, their anisotropic properties allow for flexibility in design and can be tailored as required for optimal load paths [2]. The crashworthiness properties of composite materials must therefore be well understood.

The use of composite structures in crashworthiness applications, particularly in the form of tubes and rods has been fundamentally studied by Thornton et al. [3, 4], Hull et al. [5-8], Fairfull et al. [9, 10] and Hamada et al. [11, 12]. A lot of recent work on energy absorption and crashworthiness of composite materials in axial compression has also been performed by Yang et al. [13], Ma et al. [14], Xu et al. [15], Kathiresan et al. [16], Sun et al. [17], Wang et al. [18], Atthapreyangkul et al. [19], Eshkoor et al. [20], and Alkbir et al. [21]. The authors [3-12] have shown that even if composite materials are brittle in nature compared to metals, well designed composite tubes can absorb significant amounts of energy during crushing through multiple micro-fracture processes and can exhibit a stable crushing mechanism known as progressive crushing. They reported that composite tubes that are designed with a trigger at one end such as a chamfer angle will exhibit progressive crushing behavior. During this behavior the load increases to a maximum value, and then proceeds to a constant value where progressive crushing takes place throughout the remaining structure. During progressive crushing of composite tubes, radial fiber splaying occurs outwards from 
the chamfer end until the tube is fully compacted. Splaying of fibers is a clear sign that an optimal amount of energy is being absorbed during compression.

Alia et al. [22-24] have investigated the crushing energy absorption characteristics of small composite tube and metal tube-reinforced polymer foam panels for crashworthiness applications. In addition to being lightweight, they found that the surrounding foam provided additional benefits to the crushing performance of the tubes.

Fortin et al. [25] have studied the crushing behavior and specific energy absorption of small braided glass fiber composite rods inserted in corrugated cardboard panels for automotive crashworthiness. Static compression testing was performed, and they found that the specific energy absorption of rods embedded in cardboard is superior to rods without cardboard, and that relatively thin singlelayer cardboard panels reinforced with shorter rods performed better than thicker panels with longer rods due to reduced cardboard shifting and inclination of rods. As cardboard materials are inexpensive, easy to access, and made from recycled paper, they are attractive for affordable and rapid processing of parts with benefits to the environment.

Recent work has also been done by Paruka et al. [26, 27], Harms et al. [28], Shin et al. [29], Reuter et al. [30], Kim et al. [31], Liu et al. [32], Wu et al. [33], and Zhu et al. [34] on crashworthiness of hybrid structures consisting of metals, primarily aluminum, and fiber-reinforced polymer composites. Their work focuses largely on hybrid tubular structures and sandwich panels with the aim to obtain benefits of performance, weight reduction, and low-cost from combining lightweight metals with composites in crash applications.

No previous research investigated the effect of stacked aluminum layers on the crushing behavior of hybrid polymer composites, therefore, this paper focuses on crashworthiness properties of different configurations of stacked aluminum-cardboard panels reinforced with braided glass fiber-reinforced epoxy rods manufactured using a tubular braiding machine through quasi-static compression tests.

\section{Experimental Procedures}

\subsection{Braided rods manufacturing and panel preparation}

The rods in this study consist of unidirectional glass fibers at the core covered by braided glass fibers, as manufac- tured in a previous study by Fortin et al. [25]. Fibers for the axial and braiding portions of the rod (type RS 57QM-521) have been provided by Nitto Boseki Co., Ltd. The braided preform for the rods was manufactured in an industrial tubular braiding machine. The braiding process is shown in Figure 1(a). The axial fiber bobbins were placed behind the braiding machine. A small stopper with a hole large enough to allow 18 fiber bundles to be guided was attached behind the braiding machine. The axial fibers were then altogether covered by the 8 braiding fiber bundles. To achieve a braiding angle of $45^{\circ}$ for a diameter of $3.5 \mathrm{~mm}$, the machine take-up speed (in pulling direction) was set to the slowest speed of $0.171 \mathrm{~m} / \mathrm{min}$ and the rotation speed of the braider was set to $18.15 \mathrm{rpm}$. At this take-up speed, one meter of rod can be braided every 5.8 minutes. Once the braided preform was long enough, generally a few meters, it was carefully cut and wound on a bobbin in preparation for the next step of the manufacturing process.

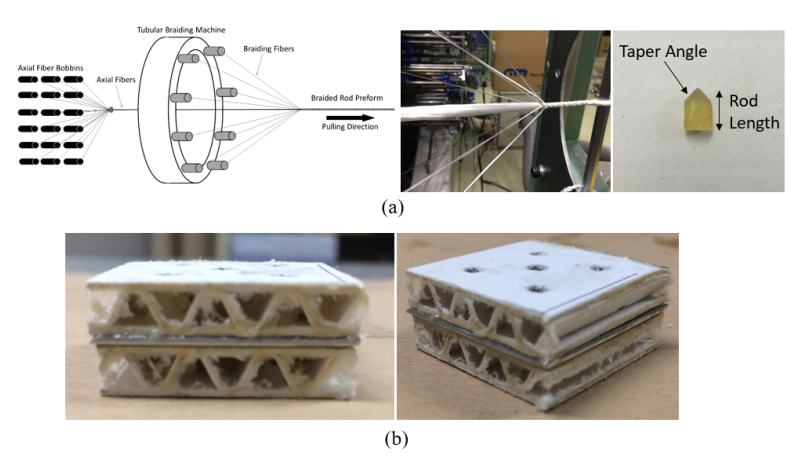

Figure 1: (a) Sketch and image of axial fiber bundles wrapped by braiding fiber bundles during the manufacturing process for fabricating rods, including a sample rod cut to length with a taper angle for compression testing; (b) Example of a sandwich structure prepared in this study consisting of corrugated cardboard, braided rods, and aluminum.

The braided preform was submerged in an epoxy resin bath and placed in a vacuum chamber oven at $80^{\circ} \mathrm{C}$ for 20 minutes to lower the resin viscosity and facilitate impregnation of the fibers. Following the impregnation step, the wet fiber preform was hung vertically from inside the ceiling of an oven for curing. The braided structure was held taught with a weight throughout the cure cycle to ensure the rods are as straight as possible. Rods were cured at $175^{\circ} \mathrm{C}$ for 4 hours. The fiber volume fraction of the composite rod is $61.7 \%$ and was determined by ignition method according to ASTM D3171 [35].

Cured glass fiber/epoxy rods were cut to a length of $6 \mathrm{~mm}$, with a high-speed cutter and then one end of each rod was ground to produce a taper angle of approximately 
$45^{\circ}$ by holding the rod tip at the correct inclination on the surface of revolving 800 grit paper on a polishing machine. An image of a braided glass rod for reinforcing the cardboard panels is also included in Figure 1(a), and the specifications for the rods are presented in Table 1 [25].

The corrugated cardboard material for making the panels in this study was supplied by Daiwa Itagami Co. Ltd, Osaka, Japan. The cardboard is $6 \mathrm{~mm}$ thick and was cut to size with a high-speed cutter. Prior to inserting the rods, a $3.4 \mathrm{~mm}$ diameter hole was drilled through the cardboard. White carpenter's glue was applied inside the hole and on the surface of the rod, and the rod was carefully pushed inside.

Aluminum sheets $1 \mathrm{~mm}$ in thickness were also cut to the same aerial dimensions as the cardboard and included in the compression panel structures as required. All cardboard and aluminum layers were bonded together with two-part epoxy resin. An example of a hybrid structure prepared in this study consisting of cardboard, braided rods, and aluminum is shown in Figure 1(b).

\subsection{Mechanical characterization}

Compression tests were performed on two-layer cardboard panels, and on five different hybrid panel structures involving two layers of cardboard with varying number and stacking order of thin aluminum sheets. Aluminum sheets were considered as structural supports for the cardboard due to its low cost and low density. Compression tests were also performed on structures with three and four layers of cardboard and two and three layers of aluminum, respectively, for the same number of composite rods. Finally, the effect of increased panel surface area was studied to confirm if this has a negative effect on the crushing performance since larger panels are a requirement for automotive structural applications. Progressive crushing behavior was evaluated from the compressive load-displacement curves, and the failure characteristics of these structures was examined visually.

Details on different hybrid sandwich structures are indicated in Table 2. Three replicates were tested for each panel configuration. In cardboard panels with rods, all rods were positioned according to the schematics of Figure 2. Different cases were also investigated with cardboard structures with and without rods and various stacking configurations of aluminum sheet as presented in Table 2. All panels were tested in compression in a Universal Testing Machine (Instron) with a 10-ton load cell at a cross-head speed of $1 \mathrm{~mm} / \mathrm{min}$. The samples were placed directly in the centre of the compression testing fixture.
Compression tests were performed until the samples were completely crushed, marked by a rapid increase in load during final compaction.
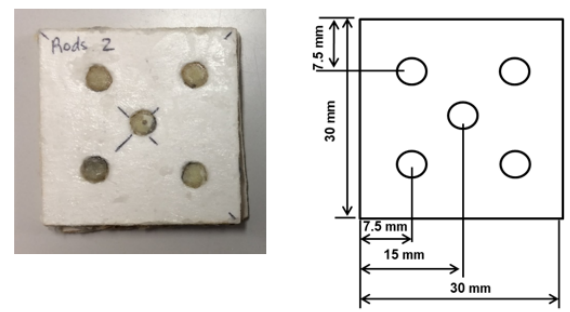

(a)
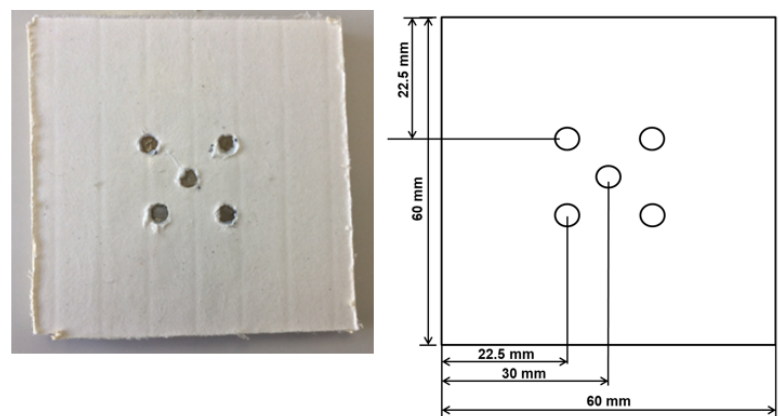

(b)

Figure 2: Dimensions and positions of rods in: (a) $30 \mathrm{~mm} \times 30 \mathrm{~mm}$ cardboard panels; (b) $60 \mathrm{~mm} \times 60 \mathrm{~mm}$ cardboard panels.

\section{Results and Discussion}

\subsection{Compression of two layers of cardboard panels}

Typical compression load-displacement data of two-layer cardboard samples reinforced with and without rods is presented in Figure 3. In two-layer samples without rods, two peaks are observed with a maximum load of $200 \mathrm{~N}$, corresponding to crushing of the individual cardboard layers in separate stages prior to final compaction. Images of the top layer being crushed first followed by the bottom layer of a two-layer cardboard structure are shown in Figure 4(a).

Typical compression load-displacement data of twolayer cardboard samples reinforced with rods is also included in Figure 3. In these samples, the load increases to just below $1400 \mathrm{~N}$, followed by a decrease to approximately $1000 \mathrm{~N}$, after which the load increases rapidly during final compaction. Despite the presence of rods, the load is not constant and the panel does not exhibit progressive crushing behavior. Previous work by Fortin et al. [25] has shown 
Table 1: Braided glass fiber rod material specifications [25].

\begin{tabular}{|c|c|c|c|c|c|c|c|}
\hline $\begin{array}{l}\text { Glass Fiber } \\
\text { Bundle Tex } \\
(\mathrm{g} / 1000 \mathrm{~m})\end{array}$ & $\begin{array}{l}\text { Number of } \\
\text { Axial Fiber } \\
\text { Bundles }\end{array}$ & $\begin{array}{l}\text { Number of } \\
\text { Braided } \\
\text { Fiber } \\
\text { Bundles }\end{array}$ & $\begin{array}{l}\text { Braiding } \\
\left.\text { Angle ( }{ }^{\circ}\right)\end{array}$ & $\begin{array}{l}\text { Rod Cross } \\
\text { Sectional } \\
\text { Area, } A \\
\left(\mathrm{~m}^{2}\right)\end{array}$ & $\begin{array}{l}\text { Fiber } \\
\text { Volume } \\
\text { Fraction } \\
(\%)\end{array}$ & $\begin{array}{l}\text { Rod } \\
\text { Density, } \rho \\
\left(\mathrm{g} / \mathrm{m}^{3}\right)\end{array}$ & $\begin{array}{l}\text { Rod } \\
\text { Specific } \\
\text { Energy } \\
\text { Absorption } \\
(\mathrm{kJ} / \mathrm{kg})\end{array}$ \\
\hline 575 & 18 & 8 & 45 & $9.08 \times 10^{-6}$ & 61.7 & $1.99 \times 10^{6}$ & 68.9 \\
\hline
\end{tabular}

Table 2: Compression testing panels.

\begin{tabular}{ll}
\hline $\begin{array}{l}\text { Panel stacking configuration, top to } \\
\text { bottom }\end{array}$ \\
C: Cardboard layer \\
A: Aluminum layer \\
\hline CC \\
CC + Rods \\
\hline ACCA & $30 \times 30$ \\
ACCA + Rods & $30 \times 30$ \\
\hline ACAC & $30 \times 30$ \\
ACAC + Rods & $30 \times 30$ \\
\hline CACA & $30 \times 30,60 \times 60$ \\
\hline CACA + Rods & $30 \times 30$ \\
\hline CAAC & \\
\hline CAAC + Rods & $30 \times 30$ \\
\hline CAC & \\
\hline CAC + Rods & \\
\hline CACAC & \\
\hline CACAC + Rods & \\
\hline
\end{tabular}

that single layer panels of the same cardboard material reinforced with the same type and configuration of rods can achieve a constant load just below $10000 \mathrm{~N}$, significantly greater than in these two-layer samples. An image of a twolayer cardboard panel with rods during compression test-

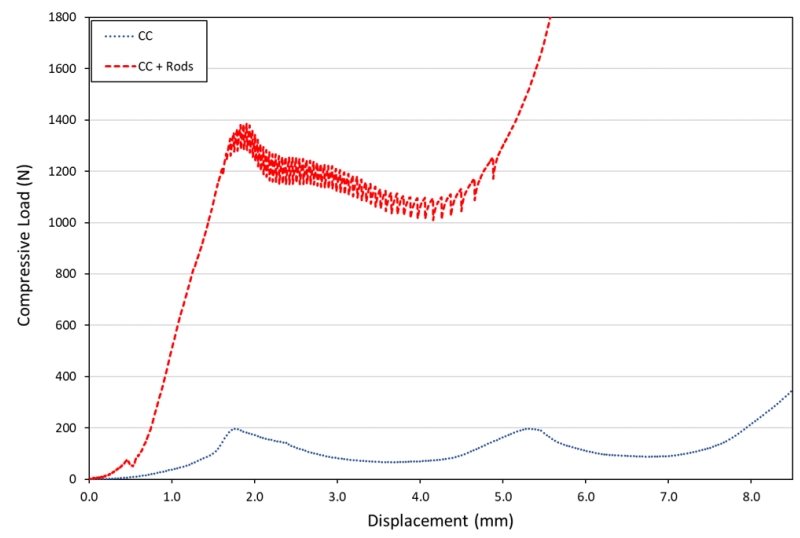

Figure 3: Load-displacement data of panels with two layers of cardboard (CC) with and without rods.

ing is shown in Figure 4(b). During crushing, significant waviness of the cardboard is observed where the top and bottom layers are in contact. Crushing of both layers is not uniform, and the top layer is also shifted considerably to the right. Crushing of the rods in both layers results in significant distortion of the cardboard in an unstable manner as seen by the waviness, resulting in the observed loaddisplacement curve with overall decreasing trend. Top and bottom surfaces of two-layer cardboard panels with rods after compression testing are shown in Figure 4(c) and (d). The top layer of cardboard has shifted relative to the bottom layer. Observation of the bottom surface of the rods in the lower layer also shows no signs of damage in the rods, due to cardboard layer shifting and so the cardboard withstands most of the loads. 


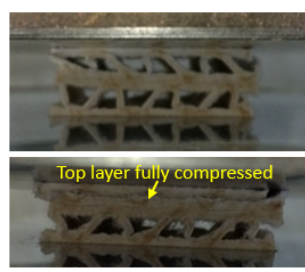

(a)

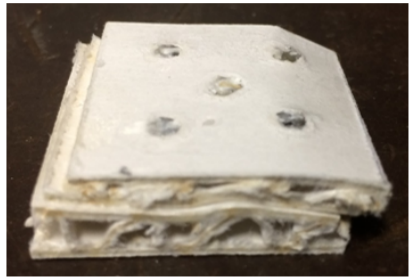

(c) (b)

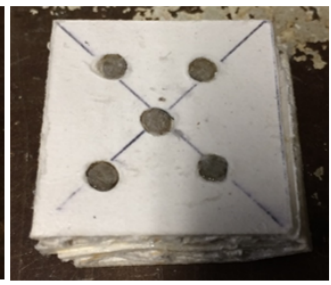

(d)

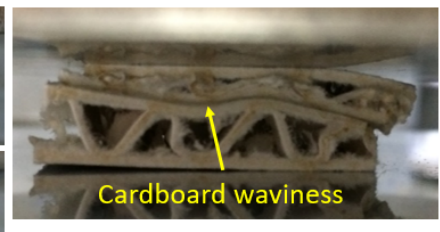

Figure 4: (a) Two-layer cardboard structure during compression testing; (b) two-layer cardboard panel with rods during compression testing; (c) top surface of two-layer cardboard panel with rods after compression testing; (d) bottom surface of two-layer cardboard panel with rods after compression testing.

\subsection{Compression of two-layer cardboard and aluminum panels with and without rods}

In an attempt to increase the thickness of the panel and the crushing distance when stacking two layers of cardboard with rods, modifications to the previous two-layer structure are required by incorporating $1 \mathrm{~mm}$-thick aluminum sheets in various configurations within two layers of cardboard.

Typical compression load-displacement data for the five different cases of two-layer cardboard structures with and without rods and various stacking configurations of aluminum sheet are presented in Figures 5 to 9. The previously obtained results for two layers of cardboard with and without rods (CC and CC + Rods) are also included in all figures for comparison. In addition, the load-displacement data of panels without rods (with and without aluminum sheets) are also shown as a separate magnified graph for better interpretation.

In the ACCA stacking configuration consisting of aluminum and cardboard only, the results are very similar to those of cardboard only (CC). When the aluminum sheets are located on the very top and bottom surfaces of the structure, they have no effect on the compression properties of the two-layer cardboard structure, as shown in Figure 5. Moreover, when rods are inserted in the cardboard layers, a maximum load of $2500 \mathrm{~N}$ is obtained after which the load then decreases to approximately $1700 \mathrm{~N}$ prior to final compaction, as shown in Figure 5. In this case, similar instability during crushing as observed in the CC +

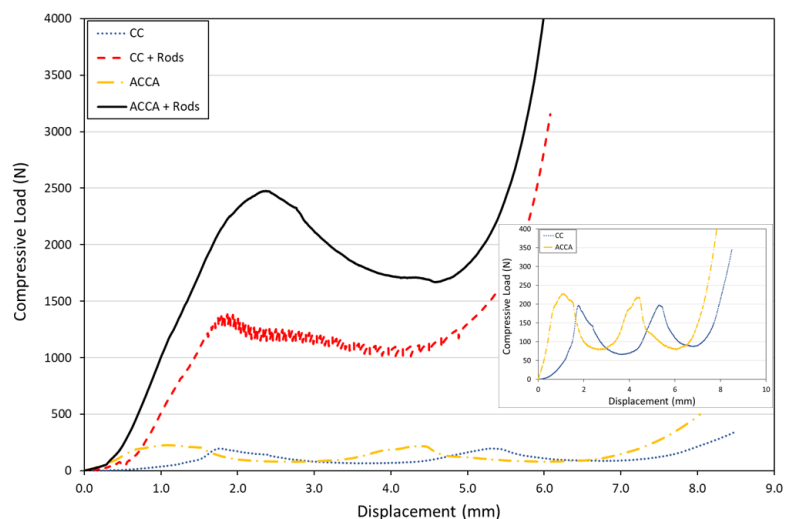

Figure 5: Load-displacement data of panels with two layers of cardboard (CC) with and without rods, and two-layers of cardboard and two layers of aluminum in a aluminum-cardboard-cardboardaluminum stacking structure (ACCA) with and without rods.

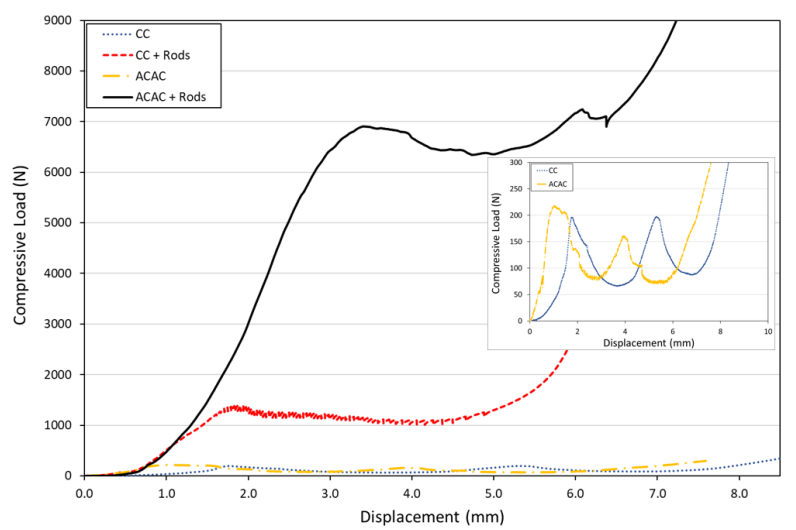

Figure 6: Load-displacement data of panels with two layers of cardboard (CC) with and without rods, and two-layers of cardboard and two layers of aluminum in a aluminum-cardboard-aluminumcardboard stacking structure (ACAC) with and without rods.

Rods sample occurs because the aluminum sheets on the top and bottom surfaces of the panel do not play a role in supporting the rods within the cardboard throughout crushing. For this reason, a constant load is not observed. However, the addition of aluminum sheets on the outermost surfaces of the panels with rods (ACCA + Rods) does increase the strength compared with panels without aluminum (CC + Rods). This is likely due to the epoxy adhesive layer in between the aluminum and cardboard that further reinforces the cardboard on the outer surfaces of the panel, and possibly interacts with the splaying and fiber fragmentation modes of the rods. If the surrounding cardboard properties at the surface are changed due to epoxy impregnation in the paper fibers, splaying of glass fiber rods will also be affected. The effect of aluminum sheets and epoxy on the topmost and bottommost layers of the 


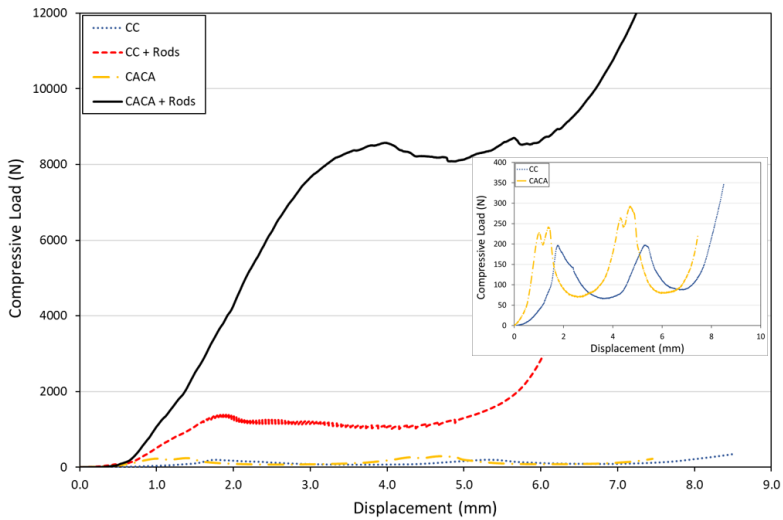

Figure 7: Load-displacement data of panels with two layers of cardboard (CC) with and without rods, and two-layers of cardboard and two layers of aluminum in a cardboard-aluminum-cardboardaluminum stacking structure (CACA) with and without rods.

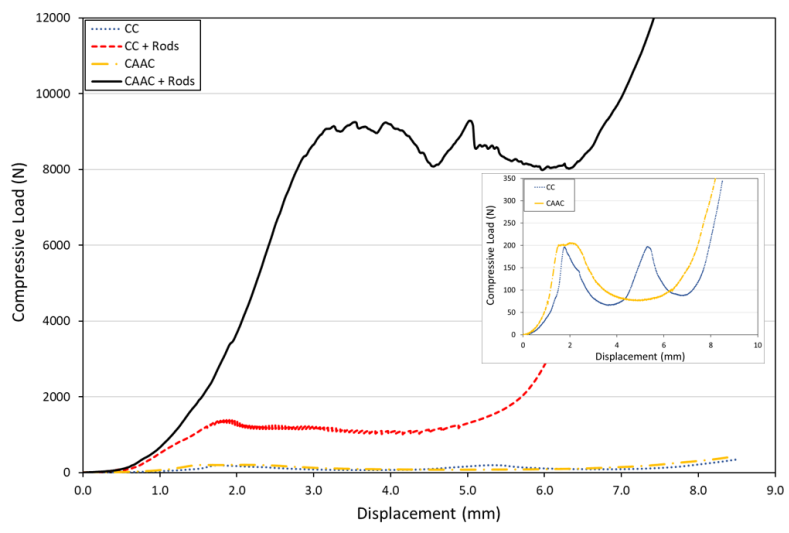

Figure 8: Load-displacement data of panels with two layers of cardboard (CC) with and without rods, and two-layers of cardboard and two layers of aluminum in a cardboard-aluminum-aluminumcardboard stacking structure (CAAC) with and without rods.

panels will be explored in additional panel configurations presented in this section.

In the ACAC configuration with aluminum and cardboard only, the results are also very similar to those of CC. The addition of one layer of aluminum on the topmost and middle layers of the panel has negligible effect on the compression properties of the cardboard structure, as shown in Figure 6. Both cardboard layers fail in the same manner, regardless of the presence of aluminum. However, when rods are added to the structure (ACAC + Rods), a significant improvement in the maximum load value and its constant progressive behavior are observed. The maximum load obtained in this stacking configuration with rods is just below $7000 \mathrm{~N}$, followed by a slight decrease to approximately $6200 \mathrm{~N}$, and then a slight gradual increase prior to final compaction, as shown in Figure 6. The addition of an aluminum sheet in between the cardboard layers certainly

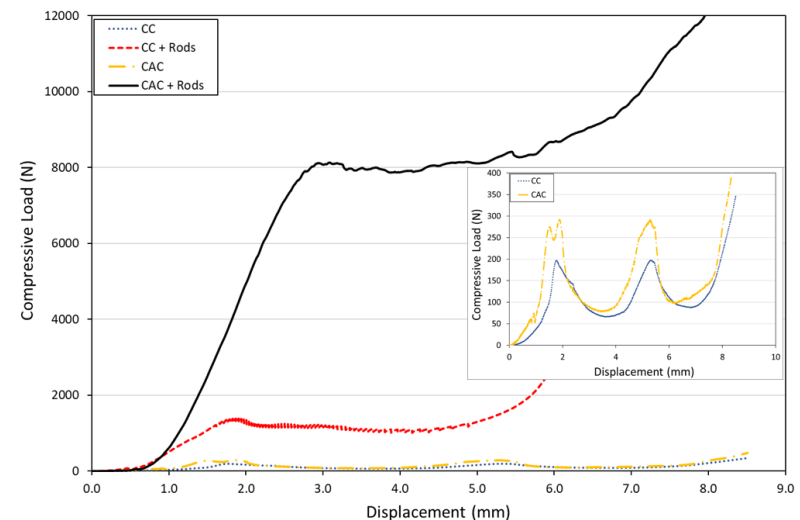

Figure 9: Load-displacement data of panels with two layers of cardboard (CC) with and without rods, and two-layers of cardboard and one layer of aluminum in a cardboard-aluminum-cardboard stacking structure (CAC) with and without rods.

plays an important role in providing stability to the rods in the panels when they are being compressed, and in ensuring that both layers of cardboard are crushed evenly with reduction in cardboard waviness and shifting of rods in adjacent layers.

For the CACA configuration, panels with no rods show similar results with CC samples as seen in previous samples. In the CACA + Rods structure, a maximum load of approximately $8050 \mathrm{~N}$ is attained, followed by a decrease to approximately $8000 \mathrm{~N}$ during crushing. Once again, the load is relatively constant and showing better signs of progressive crushing with one sheet of aluminum in between layers of cardboard, as shown in Figure 7. The maximum load is also higher compared with the previous ACAC + Rods as indicated in Figure 7 compared to that of Figure 6, suggesting that placement of one aluminum layer at the bottom as opposed to the top of the panel has benefits on the overall progressive crushing strength. In this case, when the aluminum layer is on the bottom, there is likely no effect on the behavior of the rods as splaying and fracture of the rods is initiated from the tapered tip on the top surface of a cardboard layer. When the aluminum sheet is placed on the top-most surface, the aluminum as well as the epoxy resin at the interface likely affect the mode of failure in the rods located in the top cardboard layer. Previous work by Fortin et al. [25] has shown that cardboard offers substantial benefits on the specific energy absorption of embedded rods, however, the interactions involved with aluminum stacking at the interface where rod splaying occurs likely have detrimental effects in this study. Common to the ACAC and CACA configurations is the aluminum in between cardboard layers that will surely have the same effect on the rods in the bottom layer. In the case of the CACA 
structure with a constant load just above $8000 \mathrm{~N}$, this is still lower than the previously obtained value of $10000 \mathrm{~N}$ by Fortin et al. [25] for 5 rods in a single layer of cardboard. During crushing, the aluminum sheet in between the cardboard layers will always warp slightly while supporting the rods, leading to some inefficiency in crushing energy. The interactions of the middle-layer of aluminum on the splaying mode of the underlying rods may also play a role in reducing the overall progressive crushing load, giving the results obtained in this study.

In the CAAC configuration without rods, the results are very similar to those of $\mathrm{CC}$, once again as expected. In the CAAC + Rods panel, a maximum load of approximately $9000 \mathrm{~N}$ is obtained, however significant variation occurs as the load oscillates between $8000 \mathrm{~N}$ and $9000 \mathrm{~N}$ during crushing, as shown in Figure 8. Although the maximum load is greater, likely due to additional stiffness from inserting two layers of aluminum in between the cardboard layers, the noticeable variations in load cannot be ignored and are not desirable for progressive crushing where the load should be as constant as possible. The cause for the increased variation in load is unclear. From a practical standpoint of weight reduction for a given panel thickness, as there is no significant benefit in increasing the number of aluminum layers in between cardboard from one to two, it would be favorable to only insert one layer of aluminum. For very thick panels consisting of many layers, the weight savings can be significant.

In the final configuration, CAC, the panels with rods show very good progressive crushing at $8000 \mathrm{~N}$. The load in these samples is highly constant, with very little variations, as shown in Figure 9. The CAC samples perform best out of all 5 stacking configurations. The results of this panel structure reaffirm that use of one sheet of aluminum in between cardboard layers offers desirable results. Differences in results between CAC and CACA are also not significant and therefore presence of the aluminum on the bottom-most surface likely has no effect. Furthermore, the CAC structure is better than the CACA and CAAC structures due to being of lower weight for a similar crushing performance, resulting in superior specific energy absorption.

Various stacking configurations of cardboard with aluminum have shown that it is certainly possible to increase the thickness and the associated crushing distance of single layers of cardboard reinforced with rods. Insertion of aluminum in between cardboard layers is most critical to provide stability in rods. Images of cardboard and aluminum panel configurations with and without rods after compression testing are shown in Figure 10.

When comparing the results of two layers of cardboard and the best results from two layers of cardboard with alu-

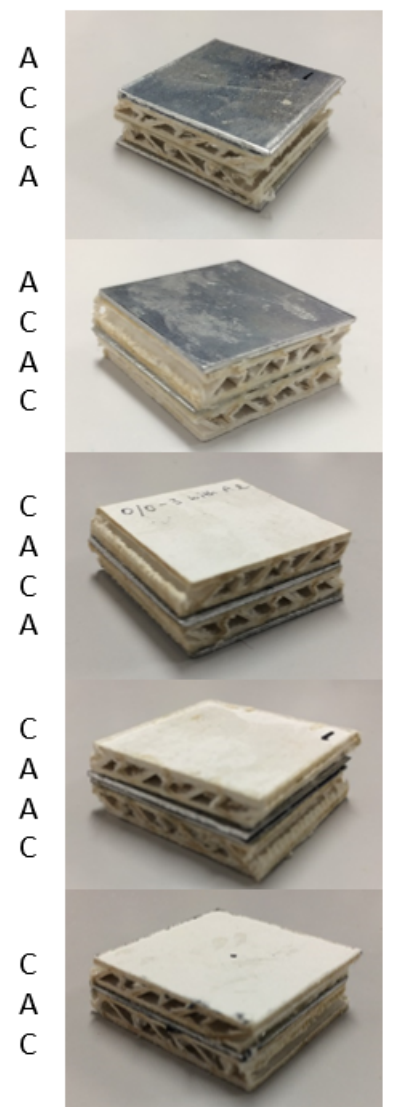

(a) (b)

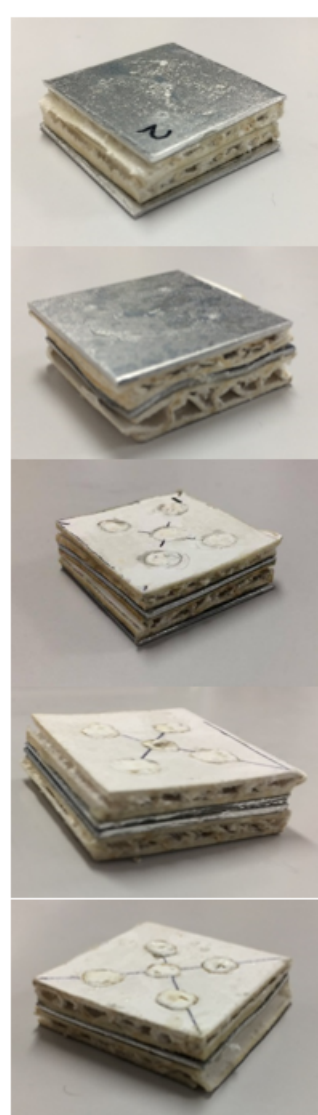

Figure 10: Images of cardboard and aluminum panel configurations after compression testing: (a) panels without rods; (b) panels with rods.

minum, significant improvements are made. In multiple layers of cardboard without aluminum, the load of each rod is transferred directly to that of the adjacent layer. As the top of the rods is tapered and the bottom is flat, direct contact of over and underlying rods in this manner is not a stable condition for load transfer. This leads to rods being inclined from the vertical and distortion of layers during compression, represented in Figure 11(a). In multiple layers with aluminum, the load exerted on each rod is transferred to the aluminum support, and then transferred uniformly to the adjacent rods, as shown in Figure 11(b).

\subsection{Compression of multi-layered sandwich structures}

Load displacement data of panels with three layers of cardboard and rods with one sheet of aluminum in between each layer (CACAC + Rods), and four layers of cardboard and rods with one sheet of aluminum in between in each 


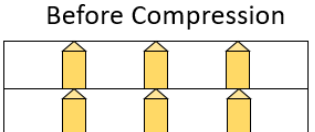

During Compression

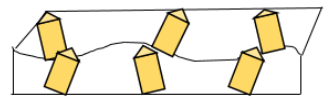

(a)
Before Compression

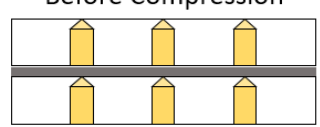

During Compression

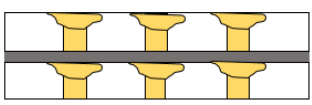

(b)
Figure 11: Sketches illustrating cardboard panels reinforced with rods without aluminum support (a) and with aluminum support (b) before and during compression. Aluminum support is required for effective load transfer and uniform crushing of adjacent layers.

layer (CACACAC + Rods) are presented in Figure 12. Data from panels with two layers of cardboard and one sheet of aluminum in between is also included for comparison. The maximum load for both three and four-layer cardboard panels is approximately the same at $6000 \mathrm{~N}$, which is significantly less than that of CAC + Rods at $8000 \mathrm{~N}$. For CACAC + Rods, the load oscillates by about 200-300 N with a mean load of $6000 \mathrm{~N}$ until final compaction. However for CACACAC + Rods, the load decreases gradually to $4500 \mathrm{~N}$ upon reaching a maximum. It is very clear that structures with both three and four layers of cardboard do not perform as well. Images of these multi-layered structures during and after compression are shown in Figure 13. In Figure 13(a), the layers are not uniformly crushed as seen by warpage of the aluminum sheets and shifting of the cardboard layers. The entire structure appears tilted in one direction. The same observations can be made in Figure 13(b). Crushing stability and uniformity that was observed with previous two-layers of cardboard and one aluminum sheet is no longer carried forward in these thicker panels. When the panels are relatively tall with a relatively small cross-sectional area, structural instability may be introduced during compression.

\subsection{The effect of panel area on multi-layered sandwich structures}

Load-displacement data of $30 \mathrm{~mm} \times 30 \mathrm{~mm}$ and $60 \mathrm{~mm}$ $\times 60 \mathrm{~mm}$ panels with CAC and CACAC stacking configurations are presented in Figure 14. Data of panels without rods is shown in Figure 14(a), and that of panels with rods in Figure 14(b). The load-displacement data for both $30 \mathrm{~mm} \times 30 \mathrm{~mm} \mathrm{CAC}$ and CACAC are very similar, characterized by two maximum peaks, as shown in Figure 14(a).

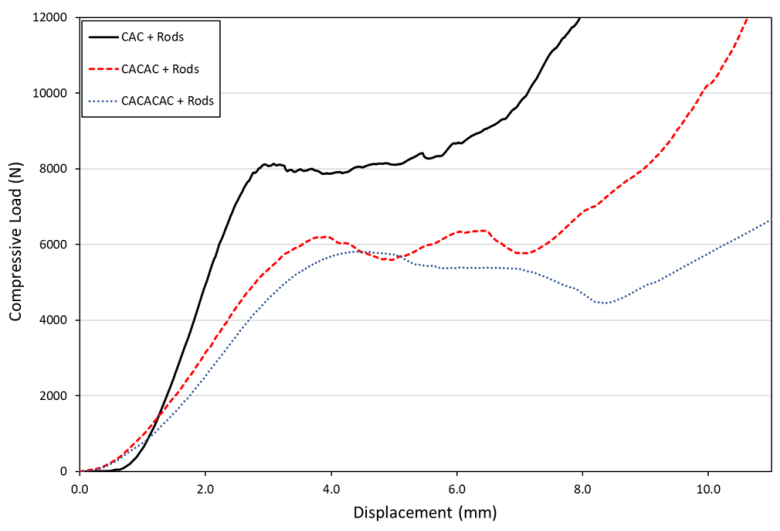

Figure 12: Load-displacement data of panels with two layers of cardboard and one layer of aluminum in between (CAC), three layers of cardboard with one layer of aluminum in between each cardboard layer (CACAC), and four layers of cardboard with one layer of aluminum in between each cardboard layer (CACACAC).

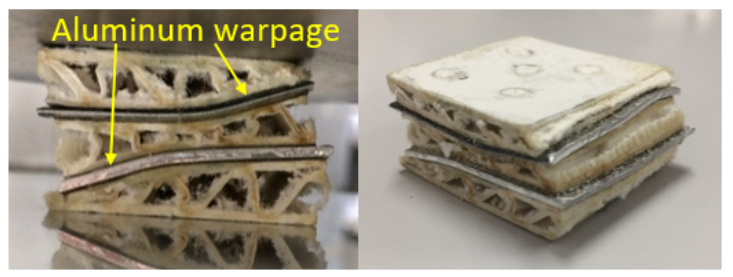

(a)

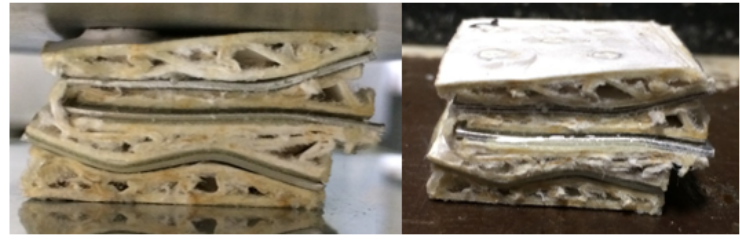

(b)

Figure 13: Images of multi-layered panel structures during and after compression testing: (a) CACAC panel structure; (b) CACACAC panel structure.

During compression of a two-layer cardboard structure, it was shown that each peak typically corresponds to crushing of an individual layer. In this case, three peaks are not seen in the CACAC structure with three layers of cardboard, as expected. However, in CACAC the onset of final compaction has been shifted to the right due to the increase in thickness. When the area of the panels is increased to $60 \mathrm{~mm} \times 60 \mathrm{~mm}$, the maximum load of all peaks increases and three peaks are now observed in the CACAC structure as opposed to two when the area is $30 \mathrm{~mm} \times 30 \mathrm{~mm}$. The reason for the difference in number of peaks as a function of area is presented in Figure 15(a) and (b). Figure 15(a) shows two-stage compression of a $30 \mathrm{~mm} \times 30 \mathrm{~mm} \mathrm{CA}$ - 
CAC sample where the top and bottom cardboard layers are compressed together first, followed by compression of the middle layer. However in Figure 15(b), three-stage compression of a $60 \mathrm{~mm} \times 60 \mathrm{~mm}$ CACAC sample is shown where the bottom cardboard layer is compressed first, followed by the top layer, and finally the middle layer. The area clearly affects the strength of each cardboard layer, and influences the order and progression of cardboard layer collapse.

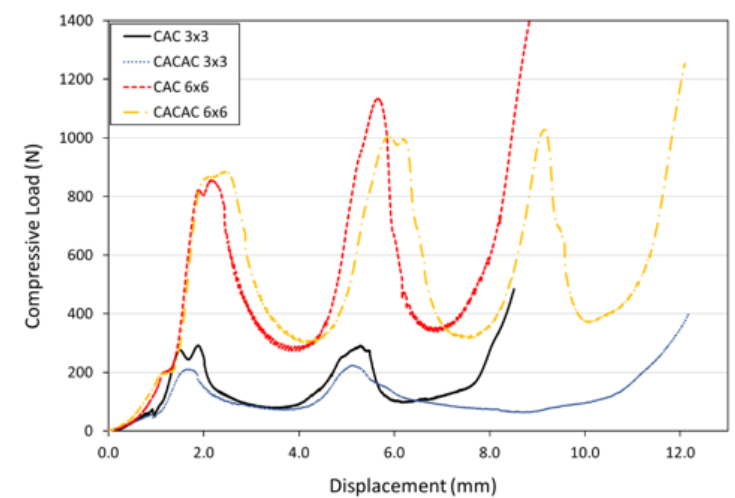

(a)

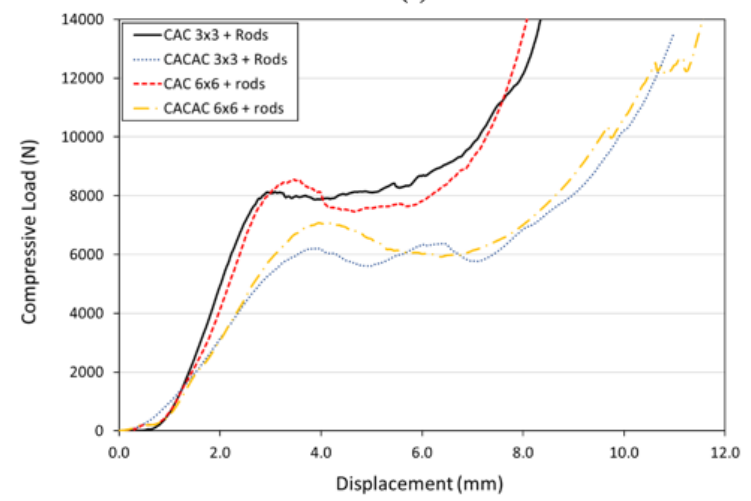

(b)

Figure 14: Load-displacement data of $3 \mathrm{~cm} \times 3 \mathrm{~cm}$ and $6 \mathrm{~cm} \times 6 \mathrm{~cm}$ panels with CAC and CACAC stacking configurations: (a) panels without rods and (b) panels with rods.

In Figure 14(b), results show that increasing the area of panels does not have a negative effect on their performance. As observed previously, the panels that perform best are the CAC configuration. CAC with an area of $60 \mathrm{~mm} \times 60 \mathrm{~mm}$ shows a maximum load that is slightly higher, however the load then decreases slightly below that of the $30 \mathrm{~mm} \times 30 \mathrm{~mm}$ CAC throughout most of the crushing. It should also be noted that in both areal dimensions, the locations and spacing of the rods were unchanged. Side, top, and bottom views of a $60 \mathrm{~mm} \times 60 \mathrm{~mm}$ CAC sample after compression are shown in Figure 15(c).

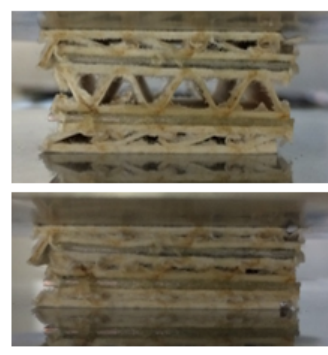

(a)

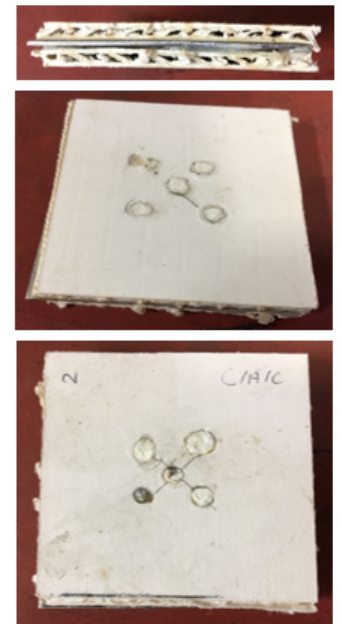

(c)

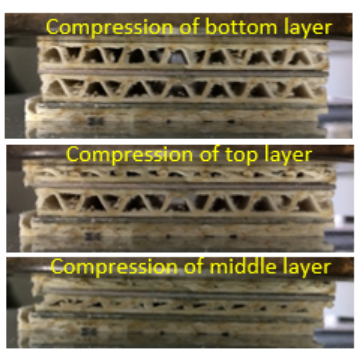

(b)

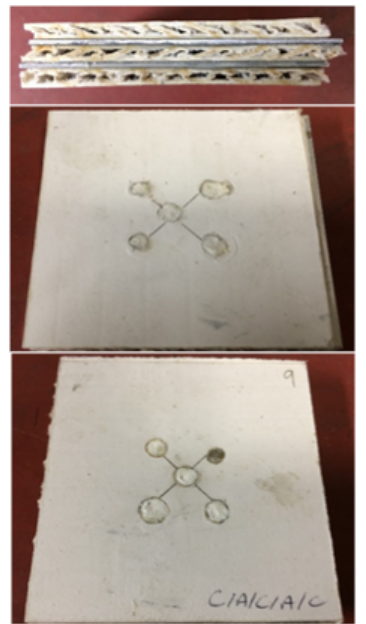

(d)
Figure 15: (a) Two-stage compression in a $30 \mathrm{~mm} \times 30 \mathrm{~mm}$ CACAC sample showing the top and bottom cardboard layers compressed together first, followed by compression of the middle layer; (b) Three-stage compression in a $60 \mathrm{~mm} \times 60 \mathrm{~mm}$ CACAC sample showing the bottom layer compressed first, followed by the top layer, and lastly the middle layer; (c) Side, top, and bottom views of a $60 \mathrm{~mm} \times 60 \mathrm{~mm}$ CAC sample; (d) Side, top, and bottom views of a $60 \mathrm{~mm} \times 60 \mathrm{~mm}$ CACAC sample.

When comparing the effect of area on CACAC structures, oscillations of the load just above and below $6000 \mathrm{~N}$ throughout crushing are seen with a smaller area. When the area is increased, the maximum load reached increases to approximately $7000 \mathrm{~N}$, but then gradually decreases to $6000 \mathrm{~N}$. A decreasing load is likely caused by factors other than the panel area such as misalignment of rods. One thing that is certain is that the load oscillations in the CACAC structure with a smaller area are not desirable for progressive crushing. Once again, the locations and spacing of the rods in both panel areas were kept the same, and additional tests to investigate their effects are required. Side, top, and bottom views of a $60 \mathrm{~mm} \times 60 \mathrm{~mm}$ CACAC sample after compression are shown in Figure 15(d). 


\section{Conclusions}

Static compression testing was performed on stacked layers of cardboard reinforced with braided glass fiber rods, and the effect of aluminum sheets in various locations in panels with two layers of cardboard was investigated. Thicker panels with three and four layers of cardboard and aluminum sheets were then tested, based on the optimal stacking configuration in the two-layer panels. The effect of panel area on crushing performance was also considered. This study showed that:

- Two layers of cardboard with rods that are stacked on top of each other with no additional support results in poor crushing performance due to instability of the rods and non-uniform deformation of the cardboard layers.

- A stacking configuration with two layers of cardboard and one aluminum sheet in between (CAC structure) gives the best results out of all five cases studied, in terms of progressive crushing and weight reduction. The aluminum was successful in allowing for uniform crushing of individual cardboard layers and rods while increasing the crushing distance compared with a single layer of cardboard. Aluminum sheet is relatively lightweight and inexpensive, making it a suitable material for stacking of braided rod-reinforced cardboard panels for increasing thickness as required in automotive structures.

- Panels of increased thickness with three and four layers of cardboard and two and three layers of aluminum, respectively, do not crush well as the structures become unstable when the thickness (number of layers) of the panel becomes noticeably greater for a relatively small surface area.

- Increasing the surface area of panels without changing the number and positioning of rods has no adverse effect on the crushing performance of panels. However, improvements to the performance of multi-layer panels with three or more layers must be achieved.

Acknowledgements: The authors would like to acknowledge Mr. Tadashi Uozumi and Dr. Akio Ohtani from Gifu University for their technical support in the operation of the braiding machine.

\section{Declaration of conflicting interests:}

The authors declare that there is no conflict of interest.

\section{Funding:}

This research received no specific grant from any funding agency in the public, commercial, or not-for-profit sectors.

\section{References}

[1] International Organization of Motor Vehicle Manufacturers. World Motor Vehicle Production by Country and Type. OICA correspondents survey, Paris, 2018.

[2] Hull D and Clyne T. An Introduction to Composite Materials. 2nd ed. Cambridge: Cambridge University Press, 1996, p. 2.

[3] Thornton PH. Energy Absorption in Composite Structures. J Compos Mater 1979; 13(3): 247-262.

[4] Thornton PH. Effect of trigger geometry on energy absorption of composite tubes. In: Proceedings of the $5^{\text {th }}$ International Conference on Composite Materials (ICCM/5), San Diego, USA, 29 July-1 August 1985. pp. 1183-1199. Warrendale, PA: Metallurgical Society.

[5] Hull D. Energy Absorption of Composite Materials under Crash Conditions. In: Hayashi T, Kawata K and Umekawa S (eds) Progress in Science and Engineering Composites. Tokyo, 1982, pp.861-870.

[6] Hull D. Axial crushing of fiber reinforced composite tubes. In: Jones N and Wierzbicki T (eds) Structural Crashworthiness. London: Butterworths, 1983, pp.118-135.

[7] Hull D and Coppola JC. Effect of trigger geometry on crushing of composite tubes. In: Benson S, Cook T, Trewin E, et al. (eds) Materials and Processing-Move into the 90's. Amsterdam: Elsevier, 1989, pp.29-38.

[8] Hull D. A Unified Approach to Progressive Crushing of FibreReinforced Composite Tubes. Compos Sci Technol 1991; 40(4): 377-421.

[9] Fairfull AH and Hull D. Effects of specimen dimensions on the specific energy absorption of fiber composite tubes. In: Mathews FL et al. (eds) Proceedings of ICCM and ECCM, Vol. 3. London: Pergamon Press, 1987, pp.3.36-3.45.

[10] Fairfull AH and Hull D. Energy absorption of polymer matrix composite structures: frictional effects. In: Wierzbicki T and Jones N (eds) Structural Failure. New York: Wiley, 1989, pp.255-279.

[11] Hamada H, Coppola JC, Hull D, et al. Comparison of energy absorption of carbon/epoxy and carbon/PEEK composite tubes. Composites 1992; 23(4): 245-252.

[12] Hamada H, Kameo K, Sakaguchi M, et al. Energy- absorption properties of braided composite rods. Compos Sci Technol 2000; 60(5): 723-729.

[13] Yang Y, Ahmed K, Zhang R, et al. A study on the energy absorption capacity of braided rod composites. Compos Struct 2018; 206: 933-940.

[14] Ma Y, Sugahara T, Yang Y, et al. A study on the energy absorption properties of carbon/aramid fiber filament winding composite tube. Compos Struct 2015; 123: 301-311.

[15] Xu J, Ma Y, Zhang Q, et al. Crashworthiness of carbon fiber hybrid composite tubes molded by filament winding. Compos Struct 2016; 139: 130-140.

[16] Kathiresan M, Manisekar K, Manikandan V. Crashworthiness analysis of glass fibre/epoxy laminated thin walled composite conical frusta under axial compression. Compos Struct 2014; 
108: 584-99.

[17] Sun G, Li S, Liu Q, et al. Experimental study on crashworthiness of empty/aluminum foam/honeycomb-filled CFRP tubes. Compos Struct 2016; 152: 969-93.

[18] Wang Y, Feng J, Wu J, et al. Effects of fiber orientation and wall thickness on energy absorption characteristics of carbonreinforced composite tubes under different loading conditions. Compos Struct 2016; 153: 356-68.

[19] Atthapreyangkul A, Prusty BG. Experimental and numerical analysis on the geometrical parameters towards the maximum SEA of CFRP components. Compos Struct 2017; 164: 229-36.

[20] Eshkoor RA, Oshkovr SA, Sulong AB, et al. Effect of trigger configuration on the crashworthiness characteristics of natural silk epoxy composite tubes. Compos Part B-Eng 2013; 55: 5-10.

[21] Alkbir MFM, Sapuan SM, Nuraini AA, et al. Fibre properties and crashworthiness parameters of natural fibre-reinforced composite structure: A literature review. Compos Struct 2016; 148: 59-73.

[22] Alia RA, Cantwell WJ, Langdon GS, et al. The energy-absorbing characteristics of composite tube-reinforced foam structures. Compos Part B-Eng 2014; 61: 127-135.

[23] Alia RA, Guan ZW, Jones N, et al. The energy-absorption characteristics of metal tube-reinforced polymer foams. J Sandw Struct Mater 2015; 17(1): 74-94.

[24] Alia RA, Guan ZW, Cantwell W], et al. A numerical study of the energy-absorption characteristics of metal tube reinforced polymer foams. J Sandw Struct Mater 2016; 18(5): 597-623.

[25] Fortin GY, Elbadry EA, Hamada H. Crashworthiness of cardboard panels reinforced with braided glass fiber rods for vehicle side impact protection. J Reinf Plast Comp. Advanced online publication. doi: $10.1177 / 0731684418796560$
[26] Paruka P, Siswanto WA, Maleque MA, et al. Crashworthy capacity of a hybridized epoxy-glass fiber aluminum columnar tube using repeated axial resistive force. J Mech Sci Technol 2015; 29(5): 1941-1953.

[27] Paruka P, Yasin MHM, Mamat R, et al. Performance Properties of Hybrid Aluminum-Composite Columnar Tube under Axial Crush Force. Adv Mat Res 2015; 1115: 288-291.

[28] Harms V, Harhash M, Carrado A, et al. Energy Absorption Behavior of Metal/Polymer/Metal Sandwich Crash Structures. KeyEng Mat 2017; 746: 275-281.

[29] Shin KC, Lee JJ, Kim KH, et al. Axial crush and bending collapse of an aluminum/GFRP hybrid square tube and its energy absorption capability. Compos Struct 2002; 57: 279-287.

[30] Reuter C, Tröster T. Crashworthiness and numerical simulation of hybrid aluminum-CFRP tubes under axial impact. Thin Wall Struct 2017; 117: 1-9.

[31] Kim HC, Shin DK, Lee JJ, et al. Crashworthiness of aluminum/CFRP square hollow section beam under axial impact loading for crash box application. Compos Struct 2014; 112: 110.

[32] Liu Q, Mo Z, Wu Y, et al. Crush response of CFRP square tube filled with aluminum honeycomb. Compos Part B-Eng 2016; 98 : 406-414.

[33] Wu Y, Liu Q, Fu J, et al. Dynamic crash responses of bio-inspired aluminum honeycomb sandwich structures with CFRP panels. Compos Part B-Eng 2017; 121: 122-133.

[34] Zhu G, Sun G, Liu Q, et al. On crushing characteristics of different configurations of metal-composites hybrid tubes. Compos Struct 2017; 175: 58-69.

[35] ASTM D3171-15, Standard Test Methods for Constituent Content of Composite Materials, ASTM International, West Conshohocken, PA, 2015, www.astm.org 